\title{
Investigation of the Predictive Power of Academic Achievement, Learning Approaches and Self-Regulatory Learning Skills on University Entrance Exam Scores Using Path Analysis
}

\author{
Dilek İlhan-Beyaztaş ${ }^{1, *} \&$ Sakine Göçer-Şahin ${ }^{2}$ \\ ${ }^{1}$ Faculty of Education, Erzincan University, Erzincan, Turkey \\ ${ }^{2}$ University of Wisconsin-Madison, USA \\ *Correspondence: Egitim Fakültesi, Erzincan Üniversitesi, Erzincan, Türkiye. E-mail:
}

dilekilhanbeyaztas@gmail.com

Received: March 29, 2018

Accepted: April 13, $2018 \quad$ Online Published: April 17, 2018

doi:10.5430/wje.v8n2p114

URL: https://doi.org/10.5430/wje.v8n2p114

\begin{abstract}
A good analysis of the success factors in the university entrance exam, which is an important step for academic careers of students, is believed to help them manage this process. Properties such as self-regulation and learning approaches adopted by students undoubtedly influence their academic achievement as well as their success in university entrance exams. However, it is not exactly known how the direct and indirect relations between these variables are, and which variable has more effect on success. This research aims to determine the extent to which university entrance exam score as dependant variable; and academic achievement, deep, surface and strategic learning approaches, four sub-dimensions of self-regulatory learning skills scale as independent variables to predict university entrance exam score directly and indirectly; to this end, a path model was developed. Within the scope of the research, the data obtained from 445 students in the $4^{\text {th }}$ class of the state-affiliated high schools in the 2016-2017 academic year were used. As a result of the research, the most important factor affecting the success of university entrance exam was found to be diploma grade; while diploma grades raise by using deep learning approaches, they fall by using surface learning approaches. It was detected that the use of the strategic learning approach reduces university entrance exam scores.
\end{abstract}

Keywords: academic achievement, learning approaches, self-regulatory learning, path analysis

\section{Introduction}

The era which we live in indicates that the basic production factor is information and emphasizes the importance of being information society. Information society, on the other hand, emphasizes the production, use and management of knowledge, and believes that this process can only be managed by individuals who have learned effective learning and have acquired high-level thinking skills. It is important to investigate how the learning process is handled, how it is organized, and what learning approaches are employed to develop the mentioned skills. In this scope, countries aim to educate qualified individuals, who are learning, creative, interrogating and able to manage the learning process properly, and focus on measurement and evaluation studies in order to select and train the qualified ones. One of the measurement and evaluation studies carried out to this end is the university entrance exams. For example, SAT (Scholastic Aptitude Tests) are applied in the USA, Matriculation Examination in Finland, General Certificate of Secondary Education in the UK, higher education institutions exam in Turkey. A good analysis of the success factors in the university entrance exam, which is an important step for academic careers of students, is believed to help them manage this process. In addition, the analysis of these factors will contribute not only to the process of entering the university but also to professional life of students. Properties such as self-regulation and learning approaches undoubtedly influence students' academic achievement as well as their success in university entrance exams (İlhan-Beyaztaş \& Senemoğlu, 2015; Pintrich \& De Groot, 1990; Ruban \& Reis, 2006; Sadler-Smith, 1996; Zimmerman \& Bandura, 1994; Zimmerman, Bandura, \& Martinez-Pons, 1992; Watkins, 2001). However, it is not exactly known how the direct and indirect relations between these variables are, and which variable has more effect on success. Accordingly, it is considered as a necessity for the scope of this study to examine the learning approaches 
that explain how students deal with the learning process, the self-regulation skills that are believed to be effective in the formation of these approaches, and the degree to which the academic achievement predicts university entrance exam; and investigate the direct and indirect relationships between these variables.

\subsection{Self-regulation}

Self-regulation is not only a behavioural skill displayed in the management of environmental conditions, but also the logic and knowledge of individual activities that are used to mobilize this skill in the relevant context (Zimmerman, 2005, p.13-14). In the literature, self-regulation is defined in different ways by different theories. When these definitions are considered in general, it can be said that self-regulation has three common features. The first of these features is the deliberate use of special processes, strategies or reactions by students to improve their academic achievement. The second feature is the feedback cycle of the teaching-learning process. This cycle shows students to see the effectiveness of the strategies and strategies used in their own learning process and, if necessary, to rearrange and modify them in response to this feedback. The third common feature is the motivational factors that cause students to use self-regulatory processes, strategies and responses (Zimmerman \& Schunk, 2001, p. 5-6). To this end, Kremer-Hayon \& Tillema (1999, pp. 508-509) reported the characteristics of self-regulated learning individuals as follows:

1. They choose and implement the most appropriate tactics and strategies to achieve the goals that they set.

2. They monitor and control their own learning and cognitive processes in an awareness of their own qualifications.

3. They organize and evaluate their own learning processes and take into account external conditions.

4. They are sure about their own learning strategies.

5. They set goals to increase their knowledge, never lose their motivation.

6. They undertake full responsibility for their successes and failures, do not blame anyone.

7. They strive to achieve success.

8. They determine their own strategies, try to reach knowledge.

\subsection{Learning Approach}

Learning approach is the motivation and attitude of the learner towards learning. However, this attitude and motivation are generally stable, but may vary according to the task and purpose of learning (Bartlett \& Burton, 2007, p. 130). The first research on learning approaches was carried out as a qualitative research by Marton and Säljö in 1976 at Göteborg University. At the end of the research; it was determined that students adopted two different learning approaches called the surface and deep approach within their learning process. In the surface learning approach, it was determined that the students head for key points / cues and attach importance to the repetition of them. In the deep learning approach, it was determined that learners focus on looking for the intention and meaning (Marton \& Säljö, 1976a, p. 4-8). In a study conducted by Ramsden in 1979, the impact of the program, teaching and assessment on students' learning was investigated and a new strategy was proposed as a "strategic learning approach" to involve students who adopt achievement and exam-oriented learning approaches (Entwistle, Hanley, \& Hounsell, 1979; Ramsden, 1979, p. 420-425).

Nearly in the same period, Biggs determined three dimensions of student study process with "Study Process Questionnaire" scale developed in 1978, taking into consideration the factors that affect the study process of the students. They were called utilizing, internalizing and achieving. The approach named utilizing is shaped by two related factors being high test anxiety and avoidance from failure. As students do not find any positive reason to work, they want to achieve their goals with the least possible effort, focusing solely on avoidance from failure (Biggs, 1979, p. 381-382). In this context, it can be said that the approach called utilization is in parallel with the surface learning approach. Intrinsic motivation of students is the basis of the approach expressed by Biggs (1979) as internalizing and students focus on finding out the meaning and relationships. In this context, it can be said that the approach called internalizing is in parallel with the deep learning approach. In the achieving approach, the third dimension of the research, students to get high grade and be successful, and to this end, they develop a well-organized study process (Biggs, 1979). It can be said that the approach called achieving is in parallel with the strategic learning approach. Within this scope learning approaches are classified as a deep, surface and strategic learning approaches within the context of learners' intention to learn. 


\subsection{Relationship between Self-Regulation, Learning Approaches, Academic Achievement and University Entrance} Exam

In the literature review, no study that directly examined the relationship between self-regulation, learning approaches, academic achievement, and university entrance exams was found. It was found that the studies that have been conducted so far usually address the relationship between self-regulation and academic achievement or learning approaches and academic achievement. These studies detected a positive correlation between self-regulation, deep and strategic learning approaches and academic success; a negative correlation between surface learning approach and academic achievement (Bernardo, 2003; İlhan-Beyaztaş \& Senemoğlu, 2015; Pintrich \& De Groot, 1990; Ruban \& Reis, 2006; Sadler-Smith, 1996; Senemoğlu, 2011; Zimmerman \& Bandura, 1994; Zimmerman, Bandura, \& Martinez-Pons, 1992; Watkins, 2001). In addition, the study conducted by Heikkilä and Lonka (2006) examined the relationship between learning approaches, self-regulation, learning strategies and achievement motivation on 366 university students studying in various departments and found a positive correlation between deep learning approach and achievement, self-regulation. A negative correlation was found between surface learning approach and achievement, self-regulation skills. Phan (2008) investigated the relationship between students' learning approach and epistemological beliefs within self-regulation and found a positive correlation between deep learning approach and self-regulation. Similarly, in the study conducted by Magno (2009), a positive correlation was found between deep learning approach and recall strategies, setting a goal, self-evaluation, seeking for help, taking responsibility and organizing sub-dimensions of self-regulatory skills, on the other hand, there was no relationship between learning approach and arranging the environment dimension. There was no relationship between the sub-dimensions of the self-regulation and surface learning approach. Similarly, in another the study conducted by Heikkilä, Niemivirta, Nieminen, and Lonka (2011) and Ekinci (2017), a positive correlation was found between deep learning approach and self-regulatory skills, while there was no relationship between surface learning approach and self-regulation. Although the studies aiming to find relationship between learning approaches and self-regulatory learning skills are limited; considering the current studies and the characteristics of the subject area, it can be said that there is a positive correlation between self-regulation and deep and strategic learning approach; and a negative correlation between surface learning approach and self-regulation. However, there has been no study that investigates how self-regulation, learning approach and academic achievement predict university entrance exam in a comprehensive and holistic approach. However, a more comprehensive analysis of these relationships is important particularly in developing curricula, determining attainable goals, constructing content, more accurate organization of teaching-learning process and increasing student achievement. In this scope, this study aims to set a path model between high school students' self-regulatory learning skills, learning approaches, academic achievement and entrance examination scores for a more comprehensive explanation of the learning process and to examine the direct and indirect relationships between these variables.

\section{Method}

This study can be defined as a relational study since it aims to examine the direct and indirect relationships between learning approaches, self-regulatory learning skills, academic achievement and university entrance exam (Frankfort-Nachmias \& Nachmias, 1992). Path analysis was used in this study. Path analysis is a type of statistical analysis carried out within the scope of structural equation modelling (SEM) studies by means of observed variables. The concept of causality discussed within the scope of SEM analysis and hence the path analysis, does not indicate experimental designs that include the investigation of manipulation-dependent change, or in other words, focus on cause-effect relationship. At this point, the concept of causality refers to the test of direct and indirect effects between variables in a context modelled by researchers (Çokluk, Şekercioğlu, \& Büyüköztürk, 2010). Causality is a process related to the design of a research rather than a statistical situation (Tabachnick \& Fidell, 2001). For this reason, an experimental research has not been designed within the scope of this study and the concept of "causality" used in interpreting the results implies the direct and indirect effects created within the scope of this model.

\subsection{Research Group}

The research data were collected from $4^{\text {th }}$ grade students of state high schools in Erzincan province in 2016-2017 academic year. Although the data were collected from 542 students, all analyzes were carried out on 462 students because no information was found regarding diploma grades of the 80 students. A study group of 445 persons was obtained by deleting 17 individuals who were determined to have univariate or multivariate outliers during the process of checking the assumptions given under the title of the data analysis. 
Table 1. Information about the Participants

\begin{tabular}{llrr}
\hline & & N & \multicolumn{1}{c}{$\%$} \\
\hline \multirow{5}{*}{ School type } & 53 & 11.9 \\
& Science High School & 30 & 6.7 \\
& Social Sciences High School & 116 & 26.1 \\
& Anatolian High School & 77 & 17.3 \\
& Anatolian Religious Vocational High School & 38.0 \\
& Vocational Technical and Anatolian High School & 169 & 38.0 \\
& Total & 445 & 100.0 \\
& Female & 276 & 62.0 \\
Gender & Male & 169 & 38.0 \\
& Total & 445 & 100.0 \\
\hline
\end{tabular}

As presented in Table 1, the data were collected from the students studying at five different school types, namely Science High School, Social Sciences High School, Anatolian High School, Anatolian Religious Vocational High School and Vocational Technical and Anatolian High School. The aim of some of the schools of which data have been collected is described by the Ministry of National Education as follows (ogm.meb.gov.tr, 2018): The aim of Science High Schools is - apart from the general aims of secondary education in Turkey- to be a source for educating students as scientists in science and mathematics fields. The Social Sciences High Schools firstly opened in Istanbul in 2003 aim - apart from the general aims of secondary education in Turkey- to be a source for educating students as scientists in literature and social sciences. Anatolian High Schools aim to prepare students for higher education by giving them a common general culture at secondary school level and to teach them at least one foreign language at a level that they can follow developments and changes in the world. According to the information obtained from the website of OSYM (Student Selection and Placement Centre), there are 117 types of high schools in Turkey. The student quota allocated to some of these schools in 2017-2018 school year is as follows: 118,669 for Science High Schools, 666,259 for Vocational Technical and Anatolian High Schools, 1,361,975 for Anatolian high schools, 36,047 for Social Sciences High Schools, and 194,674 for Religious Vocational High Schools. Among the examples given above it is observed that the highest quota is allocated to Anatolian High Schools and Vocational Technical and Anatolian High Schools and the lowest quota to Social Sciences High Schools. Concordantly, in this study, the highest participation is from Anatolian High Schools and Vocational and Technical High Schools, and the lowest participation is from Social Sciences High Schools. Therefore, it can be accepted that the selected schools are quite heterogeneous as they pose variety in terms of their aims and the numbers represent the given population of Turkey. The research group is aimed to be heterogeneous enough with the diversity of school types. $62.0 \%$ of the researchers were female and $38.0 \%$ were male. The research group is aimed to be heterogeneous enough with the diversity of school types. $62.0 \%$ of the researchers were female and $38.0 \%$ were male.

Path analysis is a type of analysis in which direct or indirect effects are investigated through observed variables and is under the framework of Structural Equation Modelling (SEM). For this reason, the assumptions for SEM are also valid for the path analysis. There is no definite number of sample sizes for SEM, and hence for the path analysis. However, it is known that more accurate estimates are made with larger samples. The simplicity / complexity of a criterion model is used to assess whether the sample size is sufficient in path analysis. According to Kline (2005), if a simple model is tested, a sample size of 100 can be considered sufficient for accurate estimates. On the other hand, the sample size of 100 is generally considered as "inadequate", sample size between 100 and 200 as "medium" and bigger than 200 as "large". If the model is complex, it is suggested that the sample size should be at least 200. Another criterion used to assess the sample size in path analysis is the number of free parameters. Accordingly, the ratio of the number of the free parameters to the sample size should be 20:1 or at least 10:1 (Kline, 2005). For example, if the number of the free parameters is 15 , the sample size should be between 150 and 300 . The number of the free parameters in the model set in the present study is 18 (the number of the free parameters is the sum of the direct effects of the exogenous variables on the covariance, variance and endogenous variables (Kline, 2005). As the exogenous variables in this study are the four sub-dimensions of self-regulatory learning skills, there are four exogenous variables, and the number of the free parameters was calculated from the correlations in the model). Accordingly, it can be said that the size of the study group in this study is sufficient for the applied path analysis, based on both the simplicity / complexity of the model and the number of the free parameters.

\subsection{Data Collection Instruments}

Within the scope of the research, "Strategic Learning Approach Scale", "Deep Learning Approach Scale" and 
"Surface Learning Approach Scale", which are composed of three subscales and developed by İlhan-Beyaztaş (2014) was used to detect learning approaches of the students and the "Self-Regulatory Learning Skills Scale" developed by Turan (2009) was used to determine self-regulatory learning skills of the students.

\subsubsection{Scales of Deep, Surface and Strategic Learning Approaches}

Each scale is unidimensional and consists of 20 five-point Likert items. Dimension and item examples of the scale were as follows:

Deep Learning Approach Scale: "The main reason for my studying is to learn more about the subjects."

Surface Learning Approach Scale:" I work as much as I need to pass a course. I think it is unnecessary to work hard."

Strategic Learning Approach Scale:" Taking a high grade is important to me."

During the development of the scales, the researcher first examined the content validity. To this end, the studies in the literature were reviewed and the criteria (critical features) which can describe "Deep Learning Approach Scale", "Surface Learning Approach Scale" and "Strategic Learning Approach Scale" that were designed to be developed. In line with these criteria, a pool consisting of 113 items was established; the item pool was checked for meeting the expected criteria, being comprehensible, being simple and being suitable for Turkish culture and Turkish by seven subject area specialists, one Turkish language teaching specialist and one measurement-evaluation specialist. In addition, these statements were discussed with respect to suitability for the purpose and comprehensibility with five students studying at the first grade of the university and revisions were made considering the criticism and recommendation. An Exploratory Factor Analysis (EFA) was conducted to examine the construct validity of the scales. The variance explained by the strategic learning approach scale was $31.36 \%$, the variance explained by the deep learning approach scale was $32.51 \%$ and the variance explained by the scale of the surface learning approach was $26.82 \%$ according to EFA results. The internal consistency coefficient (Cronbach Alpha) was calculated as 0.88 for the strategic learning approach scale, 0.89 for the deep learning approach scale and 0.86 for the surface learning approach scale (İlhan-Beyaztaş, 2014).

\subsubsection{Self-Regulatory Learning Skills Scale}

Self-regulatory learning skills scale is a Likert type 5-point scale consisting of 4 sub-dimensions and 41 items. The scale consists of the sub-dimensions of motivation and taking action to learning ( 7 items: "I take action to learn according to my interests."), planning (8 items: "I make a plan to utilize learning resources efficiently."), strategy use and evaluation (19 items: "I evaluate my learning approaches to see if they really help me learn.") and lack of self-directedness (7 items: "I wait for other people to tell me what to do in order to learn."). After a pilot study seven experts were consulted to ensure content validity. After the feedbacks, the scale consisting of 66 items, 12 of which were negative, was applied on 908 students, EFA was applied to the obtained data. As a result of the factor analysis, 41 items and four factors, were obtained based on the eigenvalues which were larger than 1.5. Four factors explained $47.10 \%$ of the total variance, the first one explained $18.36 \%$ of the total variance, the second explained $16.94 \%$, the third explained $11.95 \%$, and the fourth explained $7.87 \%$. The Cronbach's Alpha coefficients for the sub-dimensions of the scale were calculated as $0.88,0.91,0.83,0.76$ and 0.91 , respectively (Turan, 2009).

\subsection{Data Analysis}

\subsubsection{Variables of the Research}

\subsubsection{Self-Regulatory Learning Skills Scale}

Self-regulatory learning skills scale consisting of four sub-dimensions was included as independent variables in the model. Descriptive statistics of the scores taken from these four sub-dimensions are presented in Table 2.

Table 2. Descriptive Statistics of the Scores Taken from the Sub-Dimensions of the Self-Regulatory Learning Skills Scale

\begin{tabular}{lccccccc}
\hline & & & & & Standard \\
& $\mathrm{N}$ & Min & Max & $\bar{X}$ & deviation & Skewness & Kurtosis \\
\hline Motivation and taking action to learning & 445 & 16.00 & 35.00 & 28.08 & 3.75 & -.328 & .189 \\
Planning & 445 & 15.00 & 40.00 & 30.66 & 4.76 & -.287 & .003 \\
Strategy use and evaluation & 445 & 45.00 & 95.00 & 72.63 & 9.61 & -.078 & -.019 \\
Lack of self-directedness & 445 & 7.00 & 35.00 & 20.98 & 5.22 & -.022 & -.299 \\
\hline
\end{tabular}


According to Table 2, scores taken from the sub-dimension of motivation and taking action to learning range from 16.00 to 35.00 . The mean for this sub-dimension is 28.08 and the scores are normally distributed. Scores of the sub-dimension of planning range from 15.00 to 40.00 . The mean for this sub-dimension is 30.66 and the scores are normally distributed according to skewness and kurtosis coefficients. The lowest and highest scores taken from the sub-dimension of strategy use and evaluation are 45 and 95, respectively. The mean for this sub-dimension is 72.63 and the scores are normally distributed. Finally, the scores taken from the sub-dimension of lack of self-directedness range from 7.00 to 35.00 . The mean for this sub-dimension is 20.97 and the scores are normally distributed.

\subsubsection{Learning Approaches Scales}

Learning approaches scale consists of three sub-scales. A total score cannot be calculated because they do not involve only one dimension and each one was evaluated on its own. The sub-scales of deep, surface and strategic learning approaches are dependant variable for self-regulatory learning skills while they are independent variable for university entrance exam score and diploma grade. Descriptive statistics of the scores taken from these three sub-scales are presented in Table 3.

Table 3. Descriptive Statistics of the Scores Taken from the Sub-Scales of the Learning Approaches Scale

\begin{tabular}{lccccccc}
\hline & $\mathrm{N}$ & Min & Max & $\bar{X}$ & Standard deviation & Skewness & Kurtosis \\
\hline Deep & 445 & 44.00 & 100.00 & 74.03 & 10.13 & .061 & -.404 \\
Surface & 445 & 31.00 & 99.00 & 63.86 & 12.27 & .080 & -.296 \\
Strategic & 445 & 45.00 & 100.00 & 73.41 & 10.19 & -.076 & -.211 \\
\hline
\end{tabular}

According to Table 3, the scores of the deep learning approach sub-scale range from 44.00 to 100.00 . The mean is 73.03, and the scores of this sub-scale is normally distributed. The scores of the surface learning approach sub-scale range from 31.00 to 99.00 . The mean obtained from this sub-scale is 63.86. The scores of the surface learning approaches scale are normally distributed by skewness and kurtosis coefficients. Finally, the scores of the strategic learning approach scale range from 45.00 to 100.00 . The mean for this sub-dimension is 73.41 and the scores are normally distributed.

\subsubsection{Academic Achievement (Diploma grade)}

The grading system is based on 100-points for the diploma grades of the students. The students' diploma grades were not converted, raw grades were used instead. Diploma grade is dependent variable for self-regulatory learning skills and learning approaches while it is independent variable for university entrance exam score. Descriptive statistics of the diploma grades are presented in Table 4.

Table 4. Descriptive Statistics of the Diploma Grades of the Students

\begin{tabular}{cccccccc}
\hline & $\mathrm{N}$ & Min & Max & $\bar{X}$ & Standard deviation & Skewness & Kurtosis \\
\hline Diploma grades & 445 & 50.00 & 97.00 & 72.92 & 9.74 & .360 & -.593 \\
\hline
\end{tabular}

According to Table 4, the diploma grades of the students are between 50.00 and 97.00 and the mean is 72.92 . The diploma grades normally distributed according to skewness and kurtosis coefficients.

\subsubsection{University Entrance Exam Score}

The university entrance exam scores used in the research were obtained from the exam (Examination for Transition to Higher Education - YGS), which was held on March 12, 2017 and was the first stage of the examination for transition to higher education institutions. The scores obtained from YGS constitute $40 \%$ of the scores of Undergraduate Placement Exam (LYS) which is the second stage of the examination. There are six score types in YGS.

YGS1-2: Departments accepting students with numeric scores; YGS3-4: Departments accepting students with verbal scores and finally YGS5-6: Students taking students with TM (Turkish-Mathematics) scores.

In this study, six different types of scores were obtained along with the information about the numbers of correct, incorrect, empty and net answers given to the sub-tests of Basic Mathematics, Turkish, Social Sciences and Science asked in YGS. It was decided not to analyze the net numbers since the net numbers of some students were negative. Correlations between the numbers of the answers to these four sub-tests were examined. Although there was a positive and moderate correlation between the other sub-tests, no correlation between Science and Social Sciences ( $\mathrm{r}$ 
$=0.023, \mathrm{p}>0.05)$, and only a low and insignificant correlation between Basic Mathematics and Social Sciences $(\mathrm{r}=$ $0.249, \mathrm{p}>0.05$ ) overshadowed the additivity of the numbers of the correct answers to these four sub-tests. It was also decided that the tests were not one-dimensional due to the different subject scopes. The weighting of the tests also differed in the calculation of different score types. For all these reasons, the total number of correct answers was not used in the research. It is deemed appropriate to use the standardized score types calculated by OSYM on the averages of the correct numbers in this research. For each student, the highest of six different scores was taken to carry out the transactions. For example, a student has a high YGS2 score while YGS6 score of another student is higher. In this study, the highest YGS score of each student was included. Thus, the best field of each student was taken into consideration. Descriptive statistics of YGS scores of the students in all fields are presented in Table 5.

Table 5. Descriptive Statistics of YGS Scores in All Fields

\begin{tabular}{lccccccc}
\hline & & & & & Standard & & \\
& $\mathrm{N}$ & Min & Max & $\bar{X}$ & deviation & Skewness & Kurtosis \\
\hline YGS1 Score & 445 & 123 & 476 & 218.92 & 89.313 & 1.413 & .922 \\
YGS2 Score & 445 & 123 & 474 & 215.88 & 88.921 & 1.498 & 1.142 \\
YGS3 Score & 445 & 122 & 459 & 256.75 & 75.871 & .380 & -.521 \\
YGS4 Score & 445 & 120 & 451 & 246.95 & 74.511 & .460 & -.486 \\
YGS5 Score & 445 & 119 & 466 & 249.86 & 79.721 & .658 & -.229 \\
YGS6 Score & 445 & 121 & 475 & 238.59 & 85.219 & 1.054 & .310 \\
\hline
\end{tabular}

As presented in Table 5, it can be seen that YGS1, YGS2 and YGS6 scores are not normally distributed. According to the averages, it seems that the students passed the threshold of 180.00 to enter LYS which is the second step of the university placement exam in all score types. When examining the min scores obtained from all score types, it is seen that there were also students who could not pass the threshold.

The descriptive statistics of YGS score, which is the dependent variable of the research and was formed by taking the highest YGS score of the students, are presented in Table 6.

Table 6. Descriptive Statistics of YGS Scores in All Fields

\begin{tabular}{cccccccc}
\hline & $\mathrm{N}$ & Min & Max & $\bar{X}$ & Standard deviation & Skewness & Kurtosis \\
\hline YGS Score & 445 & 123.00 & 476.00 & 264.04 & 84.54 & .536 & -.428 \\
\hline
\end{tabular}

According to Table 6, YGS scores of the students included in the study range from 123.00 to 476.00 . It is seen that YGS scores, 264.04 in average, are normally distributed according to skewness and kurtosis coefficients.

The YGS score is the dependent variable of the research. It is aimed to examine the extent to which all other variables predict the YGS score directly or indirectly.

\subsubsection{Analysis of the Assumptions}

\subsubsection{Reliability}

As path analysis is based on the assumption that exogenous variables are measured without error, it is especially important for these variables to have reliable and valid psychometric properties. For this reason, the reliability of all variables (except diploma grade) collected in this study was analyzed.

Since the self-regulatory learning skills and learning approaches scales are Likert type, the reliability of these scales was calculated by Cronbach's alpha coefficient. Accordingly, the reliability of the sub-dimensions of the self-regulatory learning skills scale ranges from 0.69 to 0.88 ; and the reliability of the sub-scales of learning approaches ranges from 0.77 to 0.88 . Although the reliability coefficient for the sub-dimension of lack of self-directedness is relatively low, it can be said that this coefficient is very close to 0.70 , which is the criterion for good reliability. 
Table 7. Reliability of the Variables Included in the Research

\begin{tabular}{|c|c|c|c|}
\hline Variables / Scales & Sub-dimensions / sub-scales/sub-tests & $\begin{array}{l}\text { Number of the } \\
\text { Items }\end{array}$ & $\begin{array}{l}\text { Reliability } \\
\text { Coefficient }\end{array}$ \\
\hline \multirow{4}{*}{$\begin{array}{l}\text { Self-Regulatory Learning } \\
\text { Skills }\end{array}$} & Motivation and action to learning & 7 & 0.77 \\
\hline & Planning and goal setting & 8 & 0.83 \\
\hline & Strategies for learning and assessment & 19 & 0.88 \\
\hline & Lack of self-directedness & 7 & 0.69 \\
\hline \multirow{3}{*}{ Learning approaches } & Strategic & 20 & 0.77 \\
\hline & Deep & 20 & 0.88 \\
\hline & Surface & 20 & 0.84 \\
\hline \multirow{4}{*}{ YGS sub-tests } & Sciences & 40 & 0.98 \\
\hline & Basic Mathematics & 40 & 0.97 \\
\hline & Social Sciences & 40 & 0.88 \\
\hline & Turkish & 40 & 0.85 \\
\hline
\end{tabular}

In the research, the number of correct answers of the students in YGS sub-tests are presented, but no information is available regarding which questions were correctly answered since OSYM does not declare this information. For this reason, the reliability of YGS sub-tests was calculated using the KR-21 formula given in Equation (1), which was calculated based on the averages.

$K R-21=\frac{K}{(K-1)} *\left(1-\left(\frac{(K \bar{X})-(\bar{X})^{2}}{K S_{x}^{2}}\right)\right.$

In this formula, $\mathrm{K}$ represents the number of the items. Since item difficulty is not known in this formula, it is assumed that the items are equally difficult. According to Table 7, each of the four sub-tests asked within YGS contains 40 questions. The reliability measured through the number of the correct answers of the students participating in the research shows that the reliability of the scores obtained from the YGS sub-tests is quite high.

\subsubsection{Univariate and Multivariate Outliers}

One of the assumptions of the path analysis is that there are no single and multivariate outliers. Outliers increase the likelihood of getting unrealistic results by affecting the correlation matrix. Univariate outliers were examined by converting each variable into standard scores. 14 participants out of the $(-3,3)$ range were excluded from the research. Multivariate outliers were examined by calculating Mahalonobis distances. Three participants, who were determined to be multivariate outliers, were excluded from the study and the remaining 445 people were analyzed.

\subsubsection{Normality}

As presented in Tables 2-6, all variables are normally distributed.

\subsubsection{Multicollinearity and Singularity}

The multicollinearity problem occurs due to the high correlations between variables and the singularity occurs due to the fact that these correlations are equal to 1 . This means that variables with multicollinearity and / or singularity problem can be used interchangeably. In this case, only one of the variables is suggested to be used. The correlation matrix of the variables was examined, and it was determined that there was no correlation value over 0.90 and therefore there was no multicollinearity or singularity problem.

\subsubsection{Process}

In this study, where YGS score was dependent variable and other variables were independent variable, the extent to which the variables indirectly and directly effects YGS score was determined. Each variable was taken as an observed variable and a path model was established. The model was tested using Maximum Likelihood method with LISREL 8.7 program. Standardized factor loadings $(\lambda=$ lambda) were used to interpret the relationships between the variables in the path diagram. The standardized factor loadings give an idea of the relationship between the observed variable and the latent variable related to how a unit change in the latent variable leads to the variability in the observed variance. The high level of these values indicates a strong correlation between latent variables and observed variables (Çokluk, Şekercioğlu, \& Büyüköztürk, 2010). The fit of the model was evaluated according to the fit and error statistics. The fit and error statistics referenced in the evaluation and the criteria for their interpretation are presented in Table 8. 
Table 8. Fit and Error Statistics used in the Evaluation of the Model and Their Interpretation

\begin{tabular}{lll}
\hline & Perfect Fit & Acceptable Fit \\
\hline$\chi^{2} / \mathrm{sd}$ & $0 \leq \chi^{2} / \mathrm{sd} \leq 3$ & $3<\chi^{2} / \mathrm{sd} \leq 5$ \\
$\mathrm{RMSE}$ & $0.00 \leq \mathrm{RMSEA} \leq 0.05$ & $0.05<\mathrm{RMSEA} \leq 0.08$ \\
$\mathrm{SRMR}$ & $0.00 \leq \mathrm{RMSEA} \leq 0.05$ & $0.05<\mathrm{RMSEA} \leq 0.10$ \\
$\mathrm{GFI}$ & $0.95 \leq \mathrm{AGFI} \leq 1.00$ & $0.90 \leq \mathrm{AGFI}<0.95$ \\
$\mathrm{CFI}$ & $0.95 \leq \mathrm{AGFI} \leq 1.00$ & $0.90 \leq \mathrm{AGFI}<0.95$ \\
$\mathrm{NFI}$ & $0.95 \leq \mathrm{AGFI} \leq 1.00$ & $0.90 \leq \mathrm{AGFI}<0.95$ \\
NNFI & $0.95 \leq \mathrm{AGFI} \leq 1.00$ & $0.90 \leq \mathrm{AGFI}<0.95$
\end{tabular}

As $\chi^{2}$, one of the fit statistics presented in Table 8 , is sensitive to sample size, the difference between the expected model and the observed model increases as the sample size increases (Kline, 2005; Tabachnick \& Fidell, 2001). For this reason, the statistics obtained by dividing $\chi^{2}$ by the degree of freedom instead of $\chi^{2}$ was taken as a criterion in interpretation. According to Table 8, it is interpreted as good model fit when error statistics are close to 0 and fit statistics are close to 1 .

\section{Findings}

The model set between YGS score, diploma grade, self-regulatory learning skills and learning approaches are presented in Figure 1.

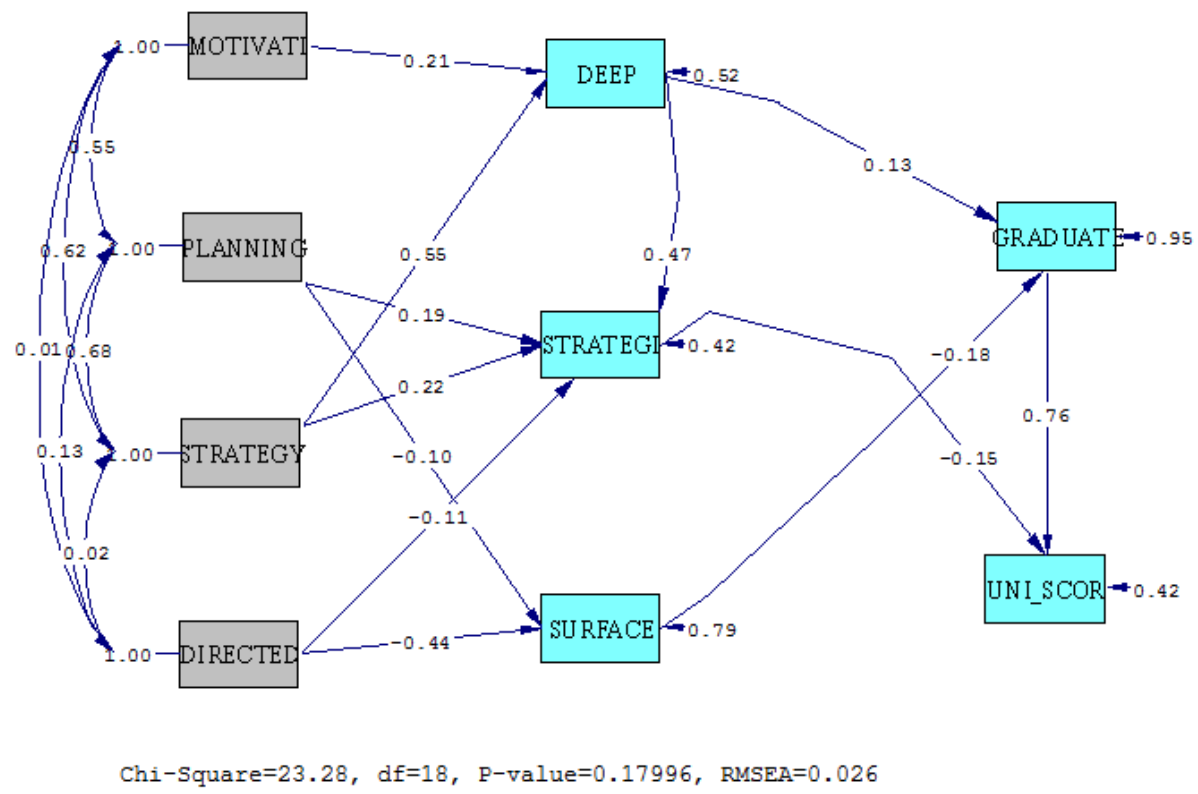

Figure 1. Standardized Coefficients-Path Diagram between YGS Score, Learning Approaches, Self-Regulatory Learning Skills and Diploma Grade

*MOTIVATI: motivation and action to learning; PLANNING: Planning and goal setting; STRATEGY: Strategies for learning and assessment; DIRECTED: lack of self-directedness; DEEP: Deep learning approach; STRATEGI: Strategic learning approach; SURFACE; Surface learning approach; GRADUATE: Graduate scores; UNI_SCOR: University entrance exam scores.

When the standardized coefficients presented in Figure 1 are examined, it seems that a unit change in lack of self-directedness leads to a -0.44 change in the surface learning approach; and a unit change in planning leads to a -0.10 change in the surface learning approach. Accordingly, as planning and lack of self-directedness skills of the students increase, surface learning approaches decrease at the specified levels. A unit change in the surface learning 
approaches has an effect of -0.18 on diploma grades. Accordingly, when students use surface learning approaches, there is a decrease of -0.18 in diploma grades.

One-unit increase in strategy use and evaluation skills has an impact of 0.22 on strategic learning approaches. Accordingly, as strategy use and evaluations skills of the students increase, the level of using strategic learning approaches increases by 0.22 . Similarly, one-unit increase in planning skills of the students has an impact of 0.19 on strategic learning approaches. Accordingly, as planning skills of the students increase, the level of using strategic learning approaches increases by 0.19 . One-unit increase in the students' use of strategic learning approaches causes an impact of -0.15 on YGS scores. Accordingly, the students' use of strategic learning approaches causes a decrease of -0.15 on YGS scores.

As the motivation of the students increases, their deep learning approaches increase. Accordingly, one-unit increase in motivation skills of the students has an increase of 0.21 on deep learning approaches. One-unit increase in strategy use and evaluation skills of the students has an impact of 0.55 on deep learning approaches. In addition, as deep learning approaches of the students increase, their skills of using strategic learning approaches. Accordingly, one-unit increase in deep learning approaches of the students has an increase of 0.47 on strategic learning approaches. Accordingly, one-unit increase in deep learning approaches of the students has an increase of 0.13 on diploma grades. Accordingly, diploma grades of the students who learn deeply increase at the specified levels. Increase in the diploma grades of the students causes an increase of 0.76 on YGS scores.

All these variables' level of explaining the change in YGS scores was determined as 58\%. Error and fit statistics of the model set between the variables are presented in Table 9 .

Table 9. Error and Fit Statistics of the Model

\begin{tabular}{lc}
\hline Error and fit statistics & Values \\
\hline$\chi^{2} /$ sd & $23.28 / 18=1.29$ \\
RMSEA & 0.026 \\
SRMR & 0.023 \\
GFI & 0.99 \\
CFI & 1.00 \\
NFI & 0.99 \\
NNFI & 0.99 \\
\hline
\end{tabular}

According to the statistics in Table 9, self-regulatory learning skills and learning approaches indirectly; diploma grades directly predict YGS scores. Accordingly, there is a perfect fit between the matched between the model established and the hypothetical model.

\section{Discussion and Conclusion}

In this study; a path model was established between self-regulation, learning approaches, academic achievement and YGS scores; and direct and indirect effects between these variables were examined. The impact, decrease or increase evaluated by associating with the literature are at the level of the coefficients obtained under the title of findings.

As a result of the established path model, it was determined that the increase in the motivation of the students caused increase in the level of adopting the deep learning approach. In the literature, it has been reported that what activates the deep learning approach is an internal motivation (Biggs, 2001, p.85; Curzon, 2004, p.232; Biggs \& Tang, 2007, p.24). In addition, it was determined that the increase in the strategy use and evaluation skills of the students caused increase in the level of adopting the deep learning approach. The key point for students with deep learning approach is to find and learn real meaning in the given task. In doing so, they develop skills such as self-assessment, self-questioning, error-detecting and error-correcting (Chin \& Brown, 2000, p.124-125). The more they develop these skills, the more meaningful they learn. In this sense, this finding of the study is in parallel to the literature. In addition, it was determined that the increase in the level of adopting the deep learning approach caused increase in the level of adopting the strategic learning approach. However, there is no finding to support this finding of the study in the literature. Although learning approaches generally display a decisive structure, this approach can change according to the task and purpose of learning (Bartlett \& Burton, 2007, p. 130). In this context, the inclusion of academic achievement in the calculation of the scores on the university entrance exam may have led the students to adopt the strategic learning approach in the process. It was detected that the fact that adopting the deep learning approach led to an increase in the diploma grade; diploma grade was also found to cause an increase in YGS scores. 
The literature also supports that the success of the individuals who adopt the deep learning approach increases (Bernardo, 2003; Heikkilä \& Lonka, 2006; İlhan-Beyaztaş \& Senemoğlu, 2015; Sadler-Smith, 1996; Watkins, 2001). YGS scores are calculated by means of a formula in which the number of the correct and incorrect answers of the students in tests and the diploma grades are also added. For this reason, it is expected that the most important variable that influences the university entrance exam scores of the students is the diploma grade. For further studies, it can be suggested to establish a similar model with raw scores calculated without students' diploma grades, if they can be obtained from OSYM.

According to the correlation between sub-dimensions of the self-regulatory learning skills and the strategic learning approach, it was determined that the increase in the strategy use and evaluation skills of the students caused increase in the level of adopting the strategic learning approach and planning skills. The key point for students with strategic learning approach is to be successful. Students who adopt this approach set goals to achieve success, plan to achieve that goal, find the right studying conditions and paths, and evaluate them by monitoring their effectiveness (Entwistle, McCune, \& Walker, 2001, p. 109). The more accurately the learning process is planned and controlled, the higher the achievement of the desired goal and the level of success are. This finding is in parallel to the literature. In addition, it was detected that the fact that adopting the strategic learning approach led to a decrease in YGS scores. In the literature, it can be seen that the success of the individuals who adopt the strategic learning approach decreases (Bernardo, 2003; Heikkilä \& Lonka, 2006; İlhan-Beyaztaş \& Senemoğlu, 2015; Sadler-Smith, 1996; Watkins, 2001). In this context, this finding contradicts with the literature. The reason for this finding may be due to the fact that the quality of the questions on the university exam is actually focused on comprehension contrary to what is believed; the individuals who adopt the strategic learning approach tend to focus on high score or success and therefore their YGS scores are low due to their lack of understanding or learning. One of the criticisms towards the university entrance exam, which consists of multiple choice items, is that students are able to answer the questions by eliminating the options, for this reason, the exam actually questions the remembering skill rather than higher level skills. In the model established within the scope of this study, the decrease in the university entrance exam scores of the students due to the use of the strategic learning approach invalidates this criticism.

According to the correlation between the sub-dimensions of the self-regulatory learning skills and the surface learning approach, it was determined that dependency on others for not undertaking the responsibility of the learning process and the increase in planning skills caused decrease in the level of adopting the surface learning approach. Since the main purpose of the surface learning approach is to overcome the task with minimum effort, the increase in planning skill decreases tendency towards the surface learning approach. This finding is in parallel to the literature (Heikkilä \& Lonka, 2006; Ilhan-Beyaztaş \& Senemoğlu, 2015; Magno, 2009). On the other hand, as the dependency on others increases during learning process, tendency towards surface learning approach decreases. This finding contradicts with the literature. In addition, it was detected that the fact that adopting the surface learning approach led to a decrease in diploma grades. In particular, students who adopt the surface learning approach exhibit a learning approach based on exploring "key points" that they consider important. The task of learning is not seen as a whole and is generally perceived as an arbitrary study of the content, as if the content is perceived as disjointed pieces. Students using this approach focus on recalling and repeating knowledge beyond the scope of the context, and the background, purpose, and subject matter to which they relate (Curzon, 2004, p.232, Biggs \& Tang, 2007, p.22). In this respect, the finding revealing that students who adopt the surface learning approach do not focus on meaning and learning is in parallel with the literature (Bernardo, 2003; Heikkilä \& Lonka, 2006; İlhan-Beyaztaş \& Senemoğlu, 2015; Sadler-Smith, 1996; Watkins, 2001).

\section{References}

Bartlett, S., \& Burton, D. (2007). Introduction to education studies. London: Sage.

Bernardo. A. B. I. (2003). Approaches to learning and academic achievement of Filipino students. Journal of Genetic Psychology, 164, 101-114. https://doi.org/10.1080/00221320309597506

Biggs, J. (1979). Individual differences in study processes and the quality of learning outcomes. Higher Education, 8(4), 381-394. https://doi.org/10.1007/BF01680526

Biggs, J. (2001). Enhancing learning: a matter of style or approach?. In R.J. Sternberg ve L. F.Zhang (Eds.), Perspective on thinking, learning, and cognitive styles, 73-102. London: Lawrence Erlbaum Associates, Inc.

Biggs, J., \& Tang, C. (2007). The Society for research into higher education teaching for quality learning at university. USA: McGraw Hill. 
Chin, C., \& Brown, D. E. (2000). Learning in science: a comparison of deep and surface approaches. Journal of $\begin{array}{llll}\text { Research in } \quad \text { Science } & \text { Teaching, } & 37(2), & 109-138 .\end{array}$ https://doi.org/10.1002/(SICI)1098-2736(200002)37:2\%3C109::AID-TEA3\%3E3.0.CO;2-7

Curzon, L. B. (2004). Teaching in further education an outline of principles and practise. New York: Continuum.

Çokluk, Ö., Şekercioğlu, G., \& Büyüköztürk, Ş. (2010). Sosyal bilimler için çok değişkenli istatistik. Ankara: Pegem Akademi.

Ekinci, N. (2017). Relationships between education faculty and engineering faculty students' critical thinking and metacognitive self-regulation strategies and their approach to learning. Journal of Educational Sciences Research, 7(2), 303-320.

Entwistle, N. J., Hanley, M., \& Hounsell, D. (1979). Identifying approach to studying. Higher Education, 8(4), 365-380. https://doi.org/10.1007/BF01680525

Entwistle, N., McCune, V., \& Walker, P. (2001). Conceptions, styles, and approaches within higher education: analytic abstractions and everyday experience. Sternberg, R.J., \& Zhang, L. F. (Eds.), Perspective on thinking, learning, and cognitive styles, 103-136. London: Lawrence Erlbaum Associates, Inc.

Frankfort-Nachmias, C., \& Nachmias, D. (1992). Research methods in the social sciences. Newyork: St. Martin's Press.

Heikkilä, A., \& Lonka , K. (2006). Studying in higher education: students' approaches to learning, self-regulation, and cognitive strategies. Studies in Higher Education, 31(1), 99-117. https://doi.org/10.1080/03075070500392433

Heikkilä, A., Niemivirta, M., Nieminen, J., \& Lonka, K. (2011). Interrelations among university students' approaches to learning, regulation of learning, and cognitive and attributional strategies a person oriented approach, High Educ, 61, 513-529. https://doi.org/10.1007/s10734-010-9346-2

İlhan-Beyaztaş, D. (2014). Başarılı Öğrencilerin Öğrenme Yaklaşımları ve Etkili Öğrenmeye İlişkin Önerileri. Unpublished Doctoral Disssertation, Hacettepe Üniversitesi Eğitim Bilimleri Enstitüsü, Ankara.

İlhan-Beyaztaş, D., \& Senemoğlu, N. (2015). Learning approaches of successful students and factors affecting their learning approaches. Education and Science, 40(179), 193-216. http://dx.doi.org/10.15390/EB.2015.4214

Kline, R. B. (2005). Principles and practice of structural equation modeling (second edition). New York: The Guilford Press.

Kremer-Hayon, L., \& Tillema, H.H. (1999). Self-Regulated learning in the context of teacher education. Teacher and Teacher Education, 15(5), 507-522. https://doi.org/10.1016/S0742-051X(99)00008-6

Magno, C. (2009). Self-Regulation and approaches to learnin in english composition writing. Tesol Journal, 1, 1-16.

Marton, F., \& Säljö, R. (1976a). On qualitative differences in learning. I-outcome and process. British Journal of Educational Psychology, 46, 4-11. https://doi.org/10.1111/j.2044-8279.1976.tb02980.x

Marton, F., \& Säljö, R. (1976b). Symposium: learning processes and strategies- II on qualitative differences in learning II-outcome as a function of the learner's conception of the task. British Journal of Educational Psychology, 46, 115-127. https://doi.org/10.1111/j.2044-8279.1976.tb02304.x

Phan, H. p. (2008). Multiple regression analysis of epistemological beliefs, learning approaches, and self-regulated learning . Electronic Journal of research in Educational Psychology, 6(1), 157-184.

Pintrich, P.R., \& De Groot, E. V. (1990). Motivational and self-regulated learning components of classroom academic performance. Journal of Educational Psychology, 82(1), 33-40. https://doi.org/10.1037/0022-0663.82.1.33

Ramsden, P. (1979). Learning and perceptions of the academic environment. Higher Education, 8(4), $411-427$. https://doi.org/10.1007/BF01680529

Ruban, L., \& Reis, S.M. (2006). Patterns of self-regulatory strategy use among lowachieving and high-achieving university students. Roeper Review, 28(3). https://doi.org/10.1080/02783190609554354

Sadler-Smith, E. (1996). Approaches to studying: age, gender and academics performance. Educational Studies, 22(3), 367-380. https://doi.org/10.1080/0305569960220306 
Senemoğlu, N. (2011). College of Education students' approaches to learning and study skills. Education and Science, 36(160), 65-80.

Tabachnick B. G., \& Fidell, L. S. (2001). Using Multivariate Statistics. USA: Pearson Education Company.

Turan, S. (2009). Probleme Dayalı Öğrenmeye İlişkin Tutumlar, Öğrenme Becerileri ve Başarı Arasındaki İlişkiler. Unpublished Doctoral Disssertation, Hacettepe Üniversitesi.

Watkins, D. (2001). Correlates of approaches to learning: A cross-cultural metaanalysis. In Stenberg, R.J. ve Zhang, L (Eds.), Perceptives on thinking, learning and cognitive styles içinde (s.165-195). London: Lawrence Erlbaum Associates, Publishers.

Zimmerman, B. J., \& Bandura, A. (1994). Impact of self-regulatory influences on writing course attainment. American Educational Research Journal, 31, 845-862. https://doi.org/10.3102/00028312031004845

Zimmerman, B. J., Bandura, A., \& Martinez-Pons, M. (1992). Selfmotivation for academic attainment: The role of self-efficacy beliefs and personal goal setting. American Educational Research Journal, 29, 663-676. https://doi.org/10.3102/00028312029003663

Zimmerman, B. J. (1989). A social cognitive view of self-regulated academic learning. Journal of Educational Psychology, 81(3), 329-339. https://doi.org/10.1037/0022-0663.81.3.329

Zimmerman, B.J. (2005). Attaining self-regulation: a social cognitive perspective. In Boekaerts, M. Pintrich, P. R. ve Zeidner M. (Eds.), Handbook of Self-Regulation, 13-39. San Diego: Academic Press.

Zimmerman, B. J., \& Schunk, D. H. (2001). Self-Regulated learning and academic achievement: theoretical perspectives. New York: Lawrence Erlbaum Associates.

http://ogm.meb.gov.tr/www/icerik_goruntule.php?KNO=657 Accessed 10.04.2018 